\title{
RENOVATION OF NMIJ'S 5 MN HYDRAULIC AMPLIFICATION TYPE FORCE STANDARD MACHINE
}

\author{
TOSHIYUKI HAYASHI, ${ }^{*}$ HIROSHI MAEJIMA and KAZUNAGA UEDA \\ National Metrology Institute of Japan (NMIJ), AIST \\ Central 3, 1-1-1 Umezono, Tsukuba, 305-8563 Japan \\ "t-hayashi@aist.go.jp \\ MITSUHARU AOKITSU \\ Maekawa Testing Machine MFG Co. Ltd. \\ 2-16-1 Omoriminami, Ota, Tokyo, 143-0013 Japan
}

\begin{abstract}
The $5 \mathrm{MN}$ hydraulic amplification type force standard machine was renovated by replacing its hydraulic pressure control system, measuring ram and cylinder. For re-evaluation of uncertainty of force amplification factor, diameters of the main and mearsuring rams and cylinders were remeasured. A programmable logic controller with a personal computer is used to control the weight motion and the valve actuation, to monitor various kinds of sensors output, and to record readings of a force transducer under calibration. Fluctuation of calibration force was suppressed by using a quartz-resonance type pressure gauge, and measurement repeatability was improved to some extent. However, there remains room for improvement to further stabilize the calibration force by modifying the measuring ram.
\end{abstract}

Keywords: Hydraulic amplification type force standard machine; automation; oil pressure; proportional-integral-derivative control; servo valve.

\section{Introduction}

Force measurements traceable to the national standard are demanded for manufacturing, building and transportation fields. Measurements of large force over $1 \mathrm{MN}$ are also required for ensuring safety of structures, power evaluation of engines and so forth. To realize large calibration forces, it is inevitable and reasonable to adopt force amplification mechanism such as levers or hydraulic cylinders.

National Metrology Institute of Japan (NMIJ) is operating a lever amplification type force standard machine of $1 \mathrm{MN}$ capacity and a hydraulic amplification type force standard machine (HFM) of 20 MN capacity. NMIJ also has another 5 MN HFM as a reserve, which could be of help during maintenance of the former two FSMs. However,

This is an Open Access article published by World Scientific Publishing Company. It is distributed under the terms of the Creative Commons Attribution 3.0 (CC-BY) License. Further distribution of this work is permitted, provided the original work is properly cited. 
this machine was not in service because it was manufactured in 1965 and had two problems: information about the amplification mechanism was not fully available and controllability of applied force was not sufficient.

The former problem concerns with the force amplification factor. Value of the amplification factor itself was recorded; however, the information was not sufficient for evaluating uncertainties of cross-sectional areas of the main and measurement rams and cylinders. Thus, diameters of the rams and cylinders had to be measured again by overhauling the hydraulic cylinders.

As for the latter problem, the $5 \mathrm{MN}$ HFM was equipped only with manual valves for pumping and releasing hydraulic oil. The operator had to keep concentrating on the valve control all the time during the calibration. Automation of the valve operation is indispensable to solve the problem.

This paper outlines the renovated pressure control mechanism and the diameter measurements.

\section{Overhaul and modification}

The 5 MN HFM consisted of a main ram to apply force to a force measuring instrument under calibration, a measuring ram to detect equilibrium between hydraulic pressure and gravitational force acting on the reference weights, a pumping unit and manual control valves. Equilibrium was monitored by using a linear variable differencial transformer (LVDT) and by operator's visual inspection through an analog voltmeter.

As the equipment was aged, we were planning to replace its component except for the rams, the cylinders and the reference weights. However, before getting down to the first plan, the 5 MN HFM was damaged by the Great East Japan Earthquake in 2011. The reference weights fell from the supporting beam, and the loading frame and the measuring cylinder were deformed permanently. Therefore, replacement of the aged component and restoration of the damaged parts were carried out at the same time.

Diameters of the main ram and cylinder were re-measured after detailed inspection on the damage and replacement of hydraulic oil seals. The measuring ram and cylinder were newly manufactured and their diameters were measured. Mass of the reference weights was re-calibrated after treating surface scratches. The pumping unit and servo valves were newly introduced as depicted in Fig. 1. Two pressure gauges were installed as shown in Fig. 2. One was of the strain-gauge type with analog continuous output and another was of the quartz-resonance type with digital discrete output. The new LVDT was installed to measure vertical position of the loading frame which is connected with the measuring ram. A programmable logic controller (PLC) was prepared for automatic control of the servo valves using readings of the pressure gauges and the LVDT. 
Main ram and cylinder

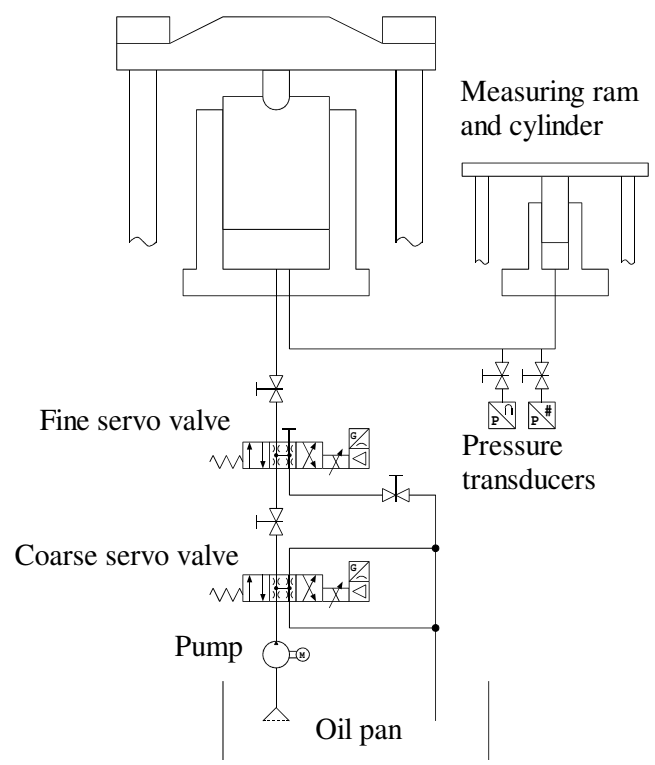

Fig. 1. Schematic of the pumping unit and servo valves.

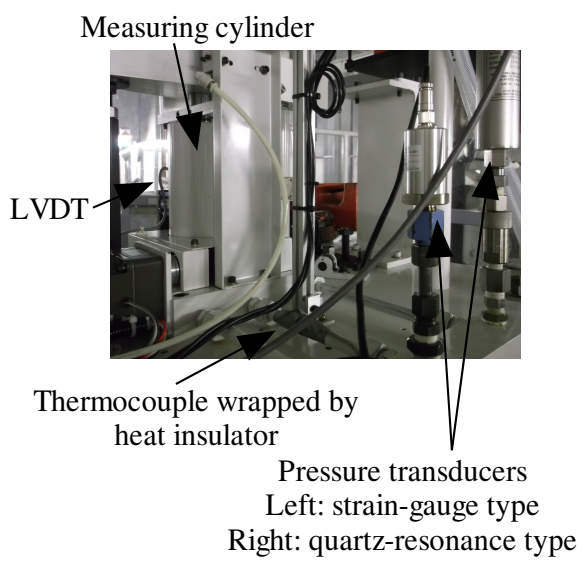

Fig. 2. Arrangement of equipment around the measuring cylinder.

\section{Diameter measurements of the rams and cylinders}

Diameters were re-measured using micrometers and a cylinder gauge, which were calibrated by referring to a set of gauge blocks traceable to the national length standard. Evaluated diameters and their uncertainties are described in Table 1.

The diameters were converted into those in $23{ }^{\circ} \mathrm{C}$, which is the ordinary room temperature in the force calibration room, while micrometers and gauge blocks were calibrated in $20^{\circ} \mathrm{C}$. Here, oil temperature in cylinders did not make much difference from 
the room temperature during 9 hours operation, since indications of two thermocouples mounted on the hydraulic pipe surfaces were always below $24{ }^{\circ} \mathrm{C}$. Because the thermocouples were wrapped in heat insulators and outer diameters of the hydraulic pipes next to the main and measuring cylinders were only $22 \mathrm{~mm}$ and $14 \mathrm{~mm}$ respectively, indications of the thermocouples well represented oil temperature in the cylinders. Though true values of coefficient of thermal expansion (CTE) of the length measuring instruments, the rams and cylinders were unknown, but these CTEs were assumed to be $(10.8 \pm 1.0) \times 10^{-6} \mathrm{~K}^{-1}$, which is a typical value of CTE for steel. Uncertainty in the CTE was taken into account.

Effective cross-sectional area of ram and cylinder was calculated using the 0th-order approximation, that is, mean value of outer diameter of the ram and bore (inner) diameter of the cylinder. Though these diameters were measured using the same combination of the reference gauge blocks, the values were regarded as independent, because uncertainties arising from resolution of the micrometers, repeatability, and difference in the CTE were dominant. Each effective cross-sectional area is also a function of the pressure. However, the amplification factor, the ratio of two cross-sectional areas, are roughly considered as uniform irrespective to the pressure change on an assumption that shapes and deformation of the main and measuring ram are homothetic. Non-uniform temperature distribution was observed between the main and measuring cylinders; accordingly, difference in thermal expansion between the two cylinders caused by the temperature difference within $1{ }^{\circ} \mathrm{C}$ was also taken into account when calculating the

Table 1(a). Uncertainty evaluation in the diameter measurements.

\begin{tabular}{|c|c|c|c|c|c|c|c|c|c|}
\hline \multirow{2}{*}{ Uncertainty source $X_{\mathrm{i}}$} & \multirow{2}{*}{ Evaluation } & \multicolumn{2}{|c|}{ Main ram } & \multicolumn{2}{|c|}{$\begin{array}{l}\text { Main } \\
\text { cylinder }\end{array}$} & \multicolumn{2}{|c|}{$\begin{array}{l}\text { Measuring } \\
\text { ram }\end{array}$} & \multicolumn{2}{|c|}{$\begin{array}{l}\text { Measuring } \\
\text { cylinder }\end{array}$} \\
\hline & & $\begin{array}{l}u\left(X_{\mathrm{i}}\right) \\
/ \mu \mathrm{m}\end{array}$ & $v\left(X_{\mathrm{i}}\right)$ & $\begin{array}{l}u\left(X_{\mathrm{i}}\right) \\
/ \mu \mathrm{m}\end{array}$ & $\nu\left(X_{\mathrm{i}}\right)$ & $\begin{array}{l}u\left(X_{\mathrm{i}}\right) \\
/ \mu \mathrm{m}\end{array}$ & $v\left(X_{\mathrm{i}}\right)$ & $\begin{array}{l}u\left(X_{\mathrm{i}}\right) \\
/ \mu \mathrm{m}\end{array}$ & $v\left(X_{\mathrm{i}}\right)$ \\
\hline Length of reference gauge-blocks & Type B & 0.65 & $\infty$ & 0.65 & $\infty$ & 0.12 & $\infty$ & 0.12 & $\infty$ \\
\hline $\begin{array}{l}\text { Resolution of micrometer at calibration } \\
\text { using reference gauge-blocks }\end{array}$ & Type B & 0.29 & $\infty$ & 0.29 & $\infty$ & 0.29 & $\infty$ & 0.29 & $\infty$ \\
\hline $\begin{array}{l}\text { Repeatability of measurement at } \\
\text { calibration using reference gauge-blocks }\end{array}$ & Type A & 0.21 & 4 & 0.29 & 7 & 0.18 & 7 & 0.18 & 7 \\
\hline $\begin{array}{l}\text { Difference in CTE between micrometer } \\
\text { and reference gauge-blocks }\end{array}$ & Type B & 0.50 & $\infty$ & 0.38 & $\infty$ & 0.02 & $\infty$ & 0.02 & $\infty$ \\
\hline $\begin{array}{l}\text { Resolution of micrometer at diameter } \\
\text { measurement }\end{array}$ & Type B & 0.29 & $\infty$ & 0.29 & $\infty$ & 0.29 & $\infty$ & 0.29 & $\infty$ \\
\hline $\begin{array}{l}\text { Repeatability of measurement at diameter } \\
\text { measurement }\end{array}$ & Type A & 0.66 & 11 & 0.90 & 11 & 0.14 & 11 & 0.15 & 11 \\
\hline $\begin{array}{l}\text { Difference in CTE between ram/cylinder } \\
\text { and micrometer }\end{array}$ & Type B & 1.9 & $\infty$ & 1.9 & $\infty$ & 0.02 & $\infty$ & 0.01 & $\infty$ \\
\hline $\begin{array}{l}\text { Uncertainty of CTE in temperature } \\
\text { difference from measurement condition }\end{array}$ & Type B & 1.3 & $\infty$ & 1.2 & $\infty$ & 0.02 & $\infty$ & 0.03 & $\infty$ \\
\hline Combined standard uncertainty of diameter & & 2.6 & 2363 & 2.6 & 744 & 0.48 & 313 & 0.49 & 306 \\
\hline
\end{tabular}

Symbols: $u\left(X_{\mathrm{i}}\right)$ and $v\left(X_{\mathrm{i}}\right)$ are standard uncertainty and degree of freedom associated with the uncertainty source $X_{\mathrm{i}}$, respectively. 
Table 1(b). Measurement results of the diameters and amplification factor.

\begin{tabular}{llll}
\hline Measurand and derived quantity & Value & $\begin{array}{l}\text { Standard } \\
\text { uncertainty }\end{array}$ & $\begin{array}{l}\text { degree of } \\
\text { freedom }\end{array}$ \\
\hline Outside diameter of main ram & $660.014 \mathrm{~mm}$ & $2.6 \mu \mathrm{m}$ & 2363 \\
Bore diameter of main cylinder & $660.612 \mathrm{~mm}$ & $2.6 \mu \mathrm{m}$ & 744 \\
Outside diameter of measuring ram & $29.228 \mathrm{~mm}$ & $0.59 \mu \mathrm{m}$ & 313 \\
Bore diameter of measuring cylinder & $29.232 \mathrm{~mm}$ & $0.59 \mu \mathrm{m}$ & 306 \\
Effective cross-sectional area of main ram-cylinder & $3.42444 \times 10^{-1} \mathrm{~m}^{2}$ & $1.9 \times 10^{-6} \mathrm{~m}^{2}$ & 2211 \\
Effective cross-sectional area of measuring ram-cylinder & $6.7104 \times 10^{-4} \mathrm{~m}^{2}$ & $1.6 \times 10^{-8} \mathrm{~m}^{2}$ & 620 \\
Force amplification factor & 510.32 & $1.6 \times 10^{-2}$ & 2252 \\
\hline
\end{tabular}

force amplification factor. Detailed evaluation of the pressure-dependent effective crosssectional area will be carried out in the future by using calibrated the quartz-resonance type pressure gauge traceable to the national pressure standard.

The diameter and uncertainty estimation of the measuring ram and cylinder in the paper are tentative, because we have a plan to re-modify the measuring ram to decrease its time constant.

\section{Force controllability}

Control of the hydraulic pressure was shared by two servo valves. In small force range, control by only using the fine servo valve caused oscillation of hydraulic pressure due to excessive pressure on the source side of the servo valve. The course servo valve supplied adequate pressure to the fine valve. The PLC controlled the course valve travel as a function of the calibration force as depicted in Fig. 3. Nevertheless, relationship between the fine valve travel and the rate of force change still exhibited nonlinearity especially on the release side of the valve as depicted in Fig. 4. The relationship was automatically obtained in the range from -25 to $25 \%$ during the first preloading cycle and was used for the control. The fine valve travel exceeding $\pm 25 \%$ was applied only for fast force increasing and decreasing in the middle range between the previous and the next calibration force steps.

At the original plan, hydraulic pressure equilibrium would have been maintained only by observation of the LVDT and control of the servo valves. However, trial of suppressing hydraulic pulsation had failed due to excessively large time constant of the measuring ram. In the case, measurement uncertainty arising from repeatability and reproducibility became too large. At the moment, suppress of the pulsation was carried out by referring the quartz-resonance type pressure gauge in parallel with the LVDT observation. At the beginning, the PLC recorded a mean value of the pressure gauge indication during wavy control of the hydraulic pressure. After that, the PLC maintains a certain value of the pressure by PID control with readings of the pressure gauge as depicted in Fig. 5. PID coefficients were automatically adjusted during the wavy control.

By repeating calibrations of a force measuring instruments of $5 \mathrm{MN}$ capacity for a week, its sensitivity fluctuation and nonlinearity were recorded as shown in Figs. 6 and 7. Rotational position of the force transducer was fixed during all of the measurements; but 


\section{T. Hayashi et al.}

the force transducer was mounted on and removed from the FSM everyday. Relative sensitivity fluctuation at $5 \mathrm{MN}$ calibration force was $8 \times 10^{-5}$ peak-to-peak. The pressure control using the reference pressure gauge improved reproducibility of the calibration results in comparison with those using only the LVDT. Here, the calibration results were influenced not only by control residual but also by temperature fluctuation and by sensitivity drift of the force transducer itself. Particularly, temperature fluctuation directly affected to force stability when the PID maintained the hydraulic pressure by using the certain reference value of the pressure gauge. Change of the main cylinder temperature of $\pm 1{ }^{\circ} \mathrm{C}$ may cause relative change of calibration force of $4 \times 10^{-5}$ on calculation. Even though the sensitivity fluctuation was better than that of the original plan, the result was

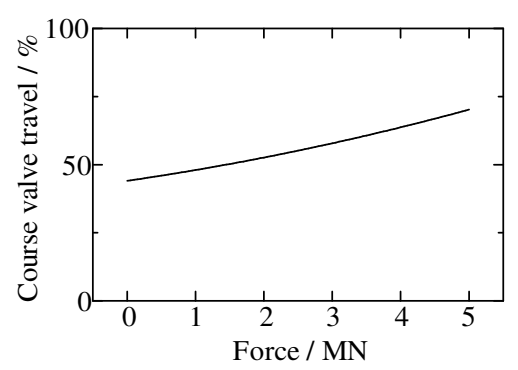

Fig. 3. The course valve travel as a function of force.

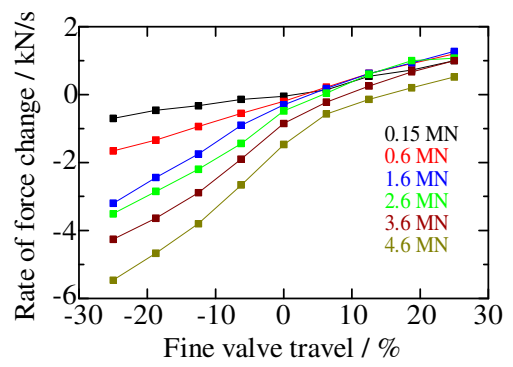

Fig. 4. Relationship between the fine valve travel and rate of force change.
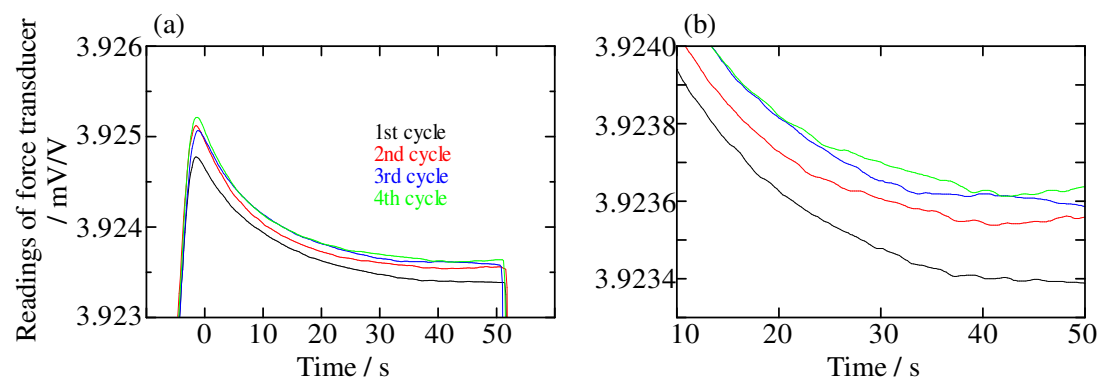

Fig. 5. Readings of a force transducer under calibration during maintaining hydraulic pressure by the PLC. (b) is an enlarged figure of (a). 


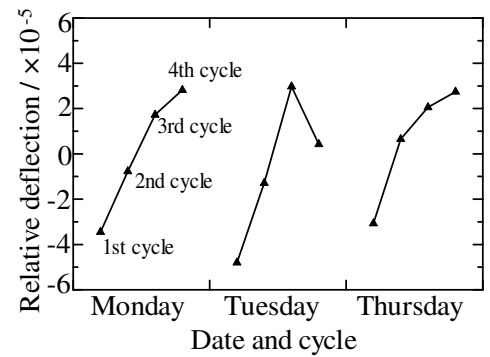

Fig. 6. Sensitivity fluctuation of a $5 \mathrm{MN}$ force transducer at $5 \mathrm{MN}$ step.

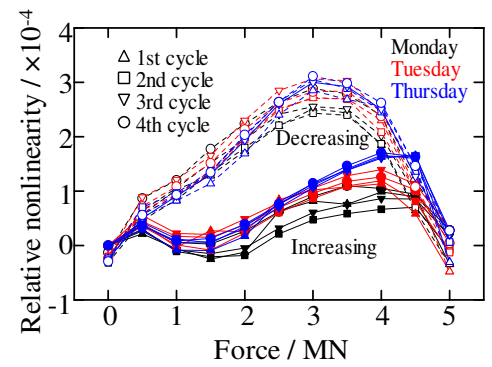

Fig. 7. Nonlinearity of a $5 \mathrm{MN}$ force transducer.

not considered to be satisfactory for a hydraulic amplification type force standard machine to be ranked as a part of the national force standards. Therefore, we are planning to re-modify the measuring ram to decrease its time constant and to further improve controllability.

\section{Summary}

The old 5 MN HFM was renovated by replacing the hydraulic pressure control system, the measuring ram and the cylinder. Diameters of the rams and cylinders were remeasured with uncertainty evaluation. The force measurement procedure at a rotational position was fully automated and measurement repeatability was improved to some extent. However, there remains room for improvement to further stabilize the calibration force by modifying the measuring ram.

\section{Acknowledgments}

The authors are grateful to Dr. Tokihiko Kobata and Dr. Hiroaki Kajikawa of NMIJ for giving valuable advice on determination of the effective cross-sectional area of the hydraulic cylinders and to Dr. Sun Jianxin of NMIJ for recalibrating the masses of the dead-weights. 